\title{
Tres poemas de Álvaro Acevedo
}

(C) UNAN-Managua

Recibido: mayo 2020 Aprobado: julio 2020

https://doi.org/10.5377/rll.v6i2.10730
Álvaro Alfonso Acevedo Merlano Universidad de la Costa, Colombia alvaroacevedomerlano@gmail.com https://orcid.org/0000-0002-0131-0276

\section{Sobre el autor}

Álvaro Alfonso Acevedo Merlano, es etnógrafo y antropólogo colombiano egresado de la Universidad del Magdalena y profesor tiempo completo de la Universidad de la Costa (CUC). Es Magister en educación de la Pontificia Universidad Javeriana y magister en comunicación y desarrollo de la Universidad Cecilio Acosta. Actualmente es el líder del grupo de investigación Community de la Universidad de la Costa; miembro del grupo de investigación sobre oralidad, narrativa audiovisual y cultura popular en el Caribe Colombiano - ORALOTECA y miembro asociado del grupo de investigaciones en diversidad humana IDHUM. Hace parte de la red mundial de escritores en español: REMES y de la Red Iberoamericana de investigadores en Anime y Manga. En su trayectoria como investigador ha participado en diversos proyectos de investigación social y ha publicado varios artículos en revistas de alto impacto además de algunos libros y textos literarios de escritura creativa

\section{LAS MAREAS DE NOVIEMBRE}

Tendrá para siempre

un recuerdo vivo

un momento de su mente

un pensamiento dueño de su vida.

Su espíritu

pertenece a los paisajes

antiguo y poderoso

hijo de la naturaleza.

\section{Eso eres tú}

el mar,

la aurora,

el amanecer.

Mis ojos...

tuyos

solo tuyos

aunque su mirar sea de otro corazón.

No quiero ser tu todo

ni tu mundo,

quiero ser

ese desquiciado

al que temes al que odias

por mostrarte la verdad

por robarte seguridad

por llenarte de incertidumbre.

No quiero ser tu mundo

aunque soy uno de tus muchos

universos posibles,

ese por el que pierdes noches enteras.

Eso es lo que quiero

diosa de los paisajes

dueña y señora

de las mareas

que me han hecho naufragar

26 en los límites impensables

de la existencia.

No hay palabra alguna

que merezca ser creída

pero los besos

la respiración sin aliento

y los latidos desenfrenados

ellos no mienten.

Quedar en silencio

y esperar que mis ojos 
te muestren la realidad que hay en mis mentiras, las que conoces las que compartimos.

\section{Una promesa} sobre mis falsas mentiras, sobre tus "Sí" en tus "No" cuando navegué sobre tus mareas.

Abandonado ahora en tierra firme recuerdo la sonrisa nerviosa que ocultaba tu deseo de mi naufragio.

Las preguntas

a mis ojos, compuertas de pocas llaves hacia mi alma.

El cruce de miradas siempre único, nadie comprendería, nadie vería el brillo segador que desprende tu alma.

¿Por qué preferir un "Te adoro" por encima de un "Te amo"? ¿Por temor a que sea una mentira?

La incredulidad evita el dolor de la desilusión, ahora entiendo por qué preferiste no creerme y lo entiendo aunque duele.

Buen viento y buena mar.

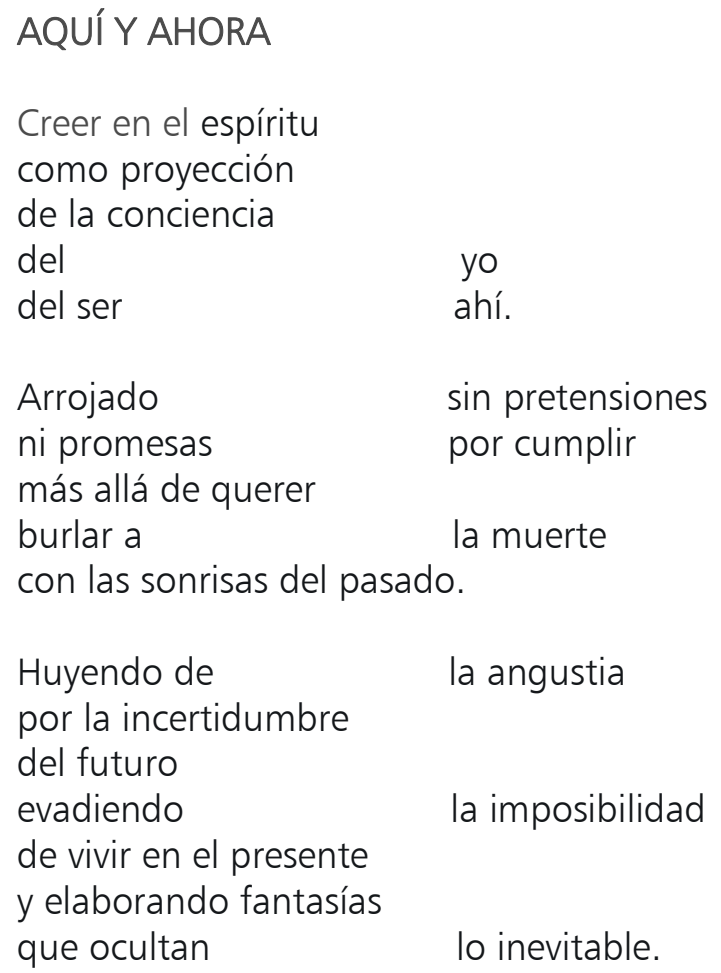

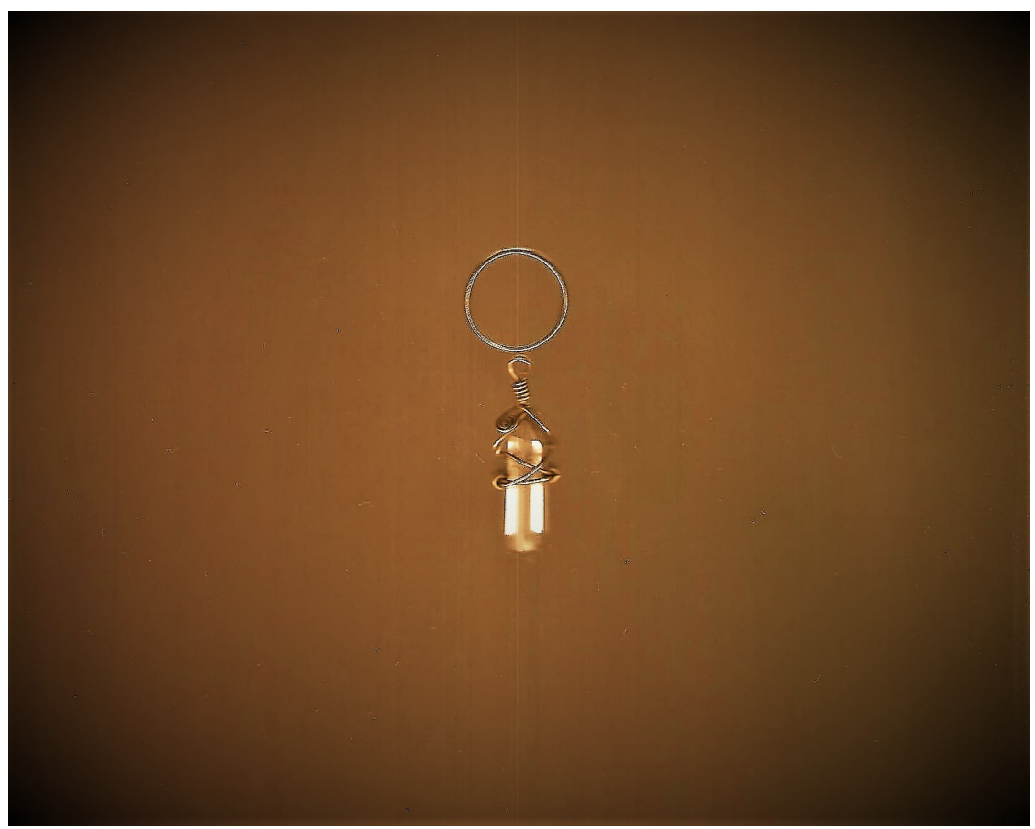




\section{OCHO AÑOS HACIA EL OLVIDO}

I

Encarnó por omisión

la condena de sus

crímenes.

Se juzgará a sí misma, será tortuoso,

será hipócrita, será moral,

será justicia.

II

Ese ocaso rojo

fue el más sentido

el más húmedo.

Y sus lágrimas,

malditas sujeciones

de persuasión

brotaron sin sentir

lamento.

\section{III}

Ella abandonó su nicho, se convirtió

en quien más odiaba, en aquel fantasma

que dejó marcado su cuerpo.

\section{IV}

Su mundo se construye destruye y reconstruye mientras sigue dando vueltas en los mismos círculos concéntricos de sus realidades paralelas.

\section{$\mathrm{V}$}

Corre a través de su último sendero temiendo de sí misma, huye de la amnesia que borrará toda huella de su pasado, evitando convertir en cenizas su único secreto.

\section{VI}

Nunca aprendió a soltar, siempre lo supo.

Deseaba aprender

a su lado, pero olvidaba sus silencios.

Prefirió

hacerlo sola, obligándome a maldecir

sus recuerdos.

VII

No crecí con una musa susurrándome al oído las artes o las ciencias, tuve que usurparlas mientras la pasión continuaba segándome con la idealización de su ser, aunque su ausencia, y su abandono fueron los creadores de mi desilusión.

VIII

Mi conciencia se diluye en el horizonte del presente matándome cada noche, obligado por el alba a continuar asfixiándome dentro de la imagen de un inacabado y falso recuerdo.

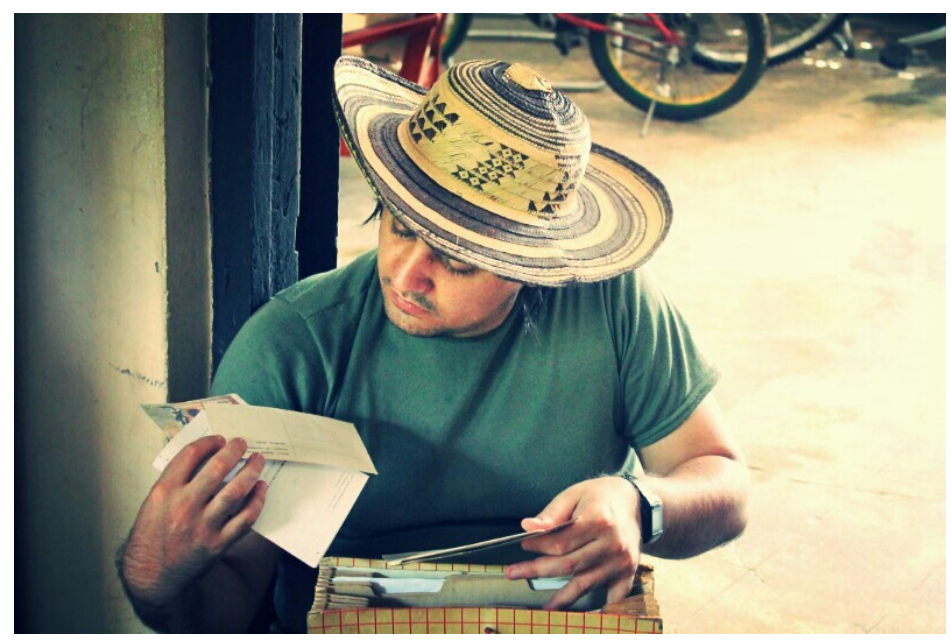

Álvaro Acevedo 